\title{
The Long Program for Ethics in Ethnobiology
}

\author{
OPEN ӘACCESS \\ DOI 10.14237/ebl.9.1.2018.1356
}

Copyright (c) 2018 by the author(s); licensee Society of Ethnobiology. This is an open-access article distributed under the terms of the Creative Commons Attribution-NonCommercial 4.0 International Public License (https://creativecommons.org/licenses/by-nc/4.0), which permits non-commercial use, distribution, and reproduction in any medium, provided the original author and source are credited.

The collection of papers in this special issue of Ethnobiology Letters emerges from an intentional multiyear concentration on ethics by the Board of Trustees of the Society of Ethnobiology (SoE). Since 2015, Scott Herron, who was SoE's President from 20152017, and Cynthia Fowler, SoE's President from 2017 -2019 , have been working together to explore ethics in ethnobiology via three main strategies. One of the Board's strategies is to engage in current issues in ethnobiology both inside and outside of the academy. Standing with humans and nonhumans who suffer social and environmental injustices is ethically imperative. To be ethical means to advocate for or against particularly pressing and relevant issues. In 2016-2018, the Board took the following actions:

- became a participating organization in the Global Campaign for the Empowerment of Indigenous Women for Zero Hunger,

- established a Memorandum of Understanding with the Latin American Society of Ethnobiology (SOLAE),

- issued a statement on the Foreign Entry Executive Order,

- declared that SoE Stands with Standing Rock and the Standing Rock Sioux Tribe in their fight as a sovereign nation against multinational Dakota Access Pipeline and its developers,

- and denounced the murder of Berta Caceres and Gustavo Castro Soto's Incarceration.

A second strategy enacted by the Board for bringing more attention to ethics in ethnobiology has been to maximize inclusivity. The SoE Board has increased financial support for key categories of existing and potential future members through its growing portfolio of fellowships and awards. The Board supports an annual Graduate Ethnobiology Research Fellowship for an Indigenous ethnobiologist, a researcher of ecological knowledge, and an urban ethnobiologist. We offer travel awards for Students, Indigenous Peoples, and ethnobiologists from outside of North America. For the forty-first annual conference, we attracted nearly $\$ 25,000$ from the Cultural Anthropology Program of the National Science Foundation, portions of which we used to cover the conference travel expenses for students, Indigenous People, and persons living outside of the United States. and Canada, as well as for the five speakers in the plenary session on Indigenous Food Sovereignty. We are grateful to Eve Emshwiller and David Spooner from the local organizing committee at the University of Wisconsin for leading the NSF application as well as to the President of the Society for Economic Botany, Gayle Fritz, for her contributions to the application. SoE has jointly met twice with Society for Economic Botany and once in association with the International Society of Ethnobiology (ISE), which has allowed us to reach broader audiences. As the Board Presidents, Fowler and Herron have supported efforts to increase the diversity of our membership by including tribal peoples in the meetings and by meeting on tribal lands in Cherokee, North Carolina in 2014. The Society overall and its meetings have become more inclusive due to these investments and outreach efforts.

A third tactic for improving the ethics-related services that SoE provides to its membership is hosting innovative ethics workshops and traditional paper sessions at our annual conferences. During the May 2016 meeting at the University of Arizona, Fowler and Herron, organized an Ethics in Ethnobiology Lab (eeLab). During the May 2017 meeting at the Montréal Botanical Gardens, Fowler and Herron hosted an evening workshop and supported the double session Engaging Communities \& Ethics in Context: The Process of Initiating Research hosted by Armando Medinaceli and Eréndira Cano. The authors of the papers in this special issue participated in these conference activities. 
The workshops and sessions at our annual conferences generated notable decisions and outcomes. A discussion about SoE's own Code of Ethics has resulted in the decision-originally made in 2010 through collaboration between SoE and ISE and then reaffirmed in 2016-to adopt ISE's Code of Ethics as its own. SoE and ISE continue to collaborate. Kelly Bannister has been a prime mover in the ISE ethics program and, from that position, is able to give readers of her article in this special issue both some background and some advice for the future evolution of ethnobiological ethics. Kelly also participated in the eeLab where she challenged us to continue exploring, "how SoE and ISE can work together in supporting Indigenous resurgence and enacting sovereign health, food, research, and governing systems."

SoE's ethics compel us to network with organizations whose values coincide or complement ours. One outcome of this is a Memorandum of Understanding (MOU) with the SOLAE. SOLAE has its own Code of Ethics, which readers of this special issue can see in SOLAE Ethics Committee et al. (2018). Armando Medinaceli from the SOLAE Ethics Committee has participated in SoE's ethics activities and, during the $2016 e e \mathrm{Lab}$, he shared with the group that the SOLAE Code of Ethics emphasizes Free Prior Informed Consent, community authorship, and communities' rights to their territories.

Like SOLAE and ISE, we feel that, as a professional academic organization, $\mathrm{SoE}$ is obliged to provide a Code of Ethics. Yet even with the adoption of the ISE Code, we do not intend for the Society to dictate how you conduct research. At the same time, we advise ethnobiologists to proceed in particular ways; for example, we urge you to develop respectful, mindful, reciprocal, long-term relationships with your collaborators. During the $2016 \mathrm{eeLab}$, Jessica Dolan shared these thoughts about the centrality of relationships in ethnobiological ethics:

Relationships that happen in the course of research are real relationships. They may be short, long, deep, shallow. They have a life of their own and the researcher is not always the one in power or control of objectives. Relationships cannot be neatly contained within the grant cycle, degree cycle, or any institutional timeline. Researchers must take care of themselves to be able to be truly reciprocitous with members of Indigenous and local communities.

Verna Miller (Pepeyla) told us during the 2016 $e e$ Lab that "we are obliged to take care of our resources." Fowler and Herron would like to add "ourselves and each other" to Verna's sentiment about caring for resources. We encourage conversation so that together we can search for answers to the seemingly endless ethics-related questions and grapple with the omnipresence of ethical concerns. We support ethnobiologists as they navigate the multilayered ethics of individuals, families, tribes, communities, institutions, nation states, and transnational organizations. We recognize the diversity of identities, knowledges, and cultures that exists among ethnobiologists and our collaborators. We recognize the existence of myriad written and unwritten codes, rules, regulations, and such. We recommend that researchers tailor their ethics for each layer and to each group of collaborators.

As an outcome of the SoE Board's emphasis on ethics, this special issue of Ethnobiology Letters represents the diversity of our members. This special issue captures the diversity of the authors' backgrounds and approaches to ethics. Ashley Blazina shares her interview with Verna Miller (Pepeyla), a member of the Nlakapamux First Nation and the President of ISE. Sophie Duncan's manifesto links common and scientific botanical terminology with racism, nationalism, and colonialism, which she illustrates with the brilliant collage on the cover of this special issue. Kelly Bannister draws on the rich history of this discipline to encourage the transformation to ethnobiological ethics as praxis. Nicole Sault offers her insights from the perspective of a scholar-activist. Will and Bhavana Tuladhar-Douglas recount the challenges that married couples face when they conduct research in the wife's native community. Shebitz and Oviedo provide a lesson plan about ethnobiological ethics for teachers who would like to use the case study method in their classrooms. Letitia McCune advocates for Indigenous Peoples' rights to their cultural relatives, especially seeds. Armando Medinaceli and his co-authors frame the reprint of the SOLAE Code of Ethics with some background on the development of our partner-organization's ethics program. In a separate article, Armando presents readers with a proposal for ethical ways to obtain consent from Indigenous People. Fowler describes 
the ways environmental ethics emerge in local communities when they are faced with dramatic disturbances in their social and environmental worlds.

We intend for the collective tone of the papers in this special issue to be more inclusive and less prescriptive. What we really wanted to do in curating these papers was to foster a genuine, good-hearted conversation, not to publish a set of diatribes. We hope you see that this special issue reflects the Board's goals to engage in advocacy, to increase inclusivity, to facilitate discussion about ethics, and to build disciplinary expertise in ethics. We also hope that you will join the conversation and help us as we continue exploring ethics in ethnobiology in the upcoming years.

Fowler and Herron as, respectively, the current President and immediate Past President have made explicit efforts to steer the Society's vision towards ethics. We would like to acknowledge the many people who have contributed to the ongoing construction of an ethics program. We are grateful to the editors of Ethnobiology Letters for allowing us to coedit the special issue and for their hard work in preparing the papers for publication, especially James Welch and Andrew Gillreath-Brown. We acknowledge the many other Society members who might have authored papers because of their experience and interest in ethics, but who were not included in this issue. We do not intend this to be an exhaustive compilation of essays by ethnobiologists who care about ethics. We recognize that many more readers of Ethnobiology Letters have important, insightful, and innovative contributions to make. Many perspectives that are not published here are worth publicizing. If this rings true to you, consider submitting your work for publication in Ethnobiology Letters and for presentation in conference sessions. We welcome you to volunteer to be a member of the Ethics and Advocacy Committee. We especially need help with becoming more active in supporting underrepresented groups and those who do not already have much support. We encourage you to contribute and participate in any ways that suit you. The Society wants to create space for your ethicsrelated ideas and activities. The future is up to you. We want to continue working with you in the spirit of learning with and listening to the Society's membership so that we can construct a participatory and collaborative ethics program. As an anonymous participant in the 2016 eeLab said, "We are people working together for common goals and common values."

\section{References Cited}

SOLAE Ethics Committee, A. Medinaceli, E. J. Cano, A. Argueta, and O. Lucia Sanabria. 2018. Latin American Society of Ethnobiology's Code of Ethics. Ethnobiology Letters 9:86-89. DOI:10.14237/

ebl.9.1.2018.1121.

July 12, 2018

Cynthia T. Fowler

Department of Sociology and Anthropology, Wofford College, Spartanburg, SC, USA.

fowlerct@wofford.edu

\section{Scott Herron}

Department of Biological Sciences, Ferris State University, Big Rapids, MI, USA. herrons@ferris.edu 